\title{
Observations on Herbage Growth, Disappearance, and Accu- mulation under Livestock Grazing
}

\author{
D.L. SCARNECCHIA AND M.M. KOTHMANN
}

\begin{abstract}
Expressing the effects of grazing animals on herbage requires explicitly defined variables describing herbage growth and herbage disappearance, as well as variables describing net changes in herbage. This paper presents a mathematical framework on variables describing herbage growth, disappearance, and accumulation, which can be used to model herbage dynamics, and to develop and present field research.
\end{abstract}

Describing herbage dynamics with or without livestock grazing requires measurement of both herbage growth and disappearance. Sequential measurements of standing crop define net changes in standing crop but do not indicate the changes that occurred in growth and disappearance. Often this distinction is essential in understanding and comparing effects of grazing management on herbage dynamics. We of ten hear that grazing systems (Society for Range Management 1974) such as short-duration grazing will maintain or increase growth rate of herbage, but less is said about effects on herbage disappearance. Similarly, in sampling during grazing studies, we usually emphasize standing crop measurements, while growth and disappearance measurements are often ignored. In general, while growth and disappearance have been frequently described and modeled in plant sciences, there is a need to mathematically formalize basic variables for application in grazing research. Quantification of dry-weight changes per unit area in standing crop, herbage growth, and herbage disappearance requires clearly defined variables developed from principles of systems analysis. Relationships among these variables should be clear and mathematical description of each variable explicit. This paper (1) defines concepts of herbage growth, herbage disappearance, and herbage accumulation; (2) offers a mathematically defined terminology for describing components of standing crop dynamics, and examines its relationship to previous papers on herbage terminology; and (3) discusses the importance of measuring herbage growth and disappearance in evaluating herbage dynamics in field grazing research.

\section{Herbage Growth}

Herbage growth has been defined by Hodgson (1979) as the development and increase in size and weight of new leaf and stem tissue. This is a functional definition of herbage growth for pasture research. Assume that during the dormant season all herbage is removed from a pasture by fire or another means, and the growth of herbage during the subsequent growing scason is measured. Herbage increases in dry weight per unit area at some herbage growth rate (HGR) (Table 1) which we could measure in $\mathrm{kg} / \mathrm{ha}$ day. HGR is a rate of new growth; it says nothing about disappearance. This variable is equivalent to what Thomas $(1980)$ defined as the gross crop growth rate, but for range and pasture work the term herbage growth rate seems more appropriate. HGR may be differentiated with respect to time to give a rate of change in $H G R$, which is nonzero any time the herbage growth rate is not constant. Integration of HGR over time gives the total summed

\footnotetext{
Authors are assistant professor, Department of Forestry and Range Management, Washington State University, Pullman $99164-6410$; and professor, Department of Range Science, Texas A \& M University, College Station 77843 .

This paper is approved by the Director, Washington State University Agricultural Research Center, as Scientific Paper 6988, Project 0617.

Manuscript accepted 28 May 1985.
}

growth of herbage, the cumulative herbage growth $(\mathrm{CHG})$, which has units of $\mathrm{kg} / \mathrm{ha}$. Because CHG is an integration over time, there is a period of time $\left(t-t_{0}\right)$ implicit in its calculation, where $t$ and $t_{0}$ are the end points of integration. Thus, cumulative herbage growth, herbage growth rate, and rate of change in herbage growth rate are a complete time-dynamic description of herbage growth.

\section{Herbage Disappearance}

Aspects of herbage disappearance have been studied in a number of field studies, e.g., Pearson (1975), Abouguendia and Whitman (1979), Ohiagu and Wood (1979), Deshmukh and Baig (1983). Important papers on range and pasture terminology (Society for Range Management 1974, Hodgson 1979, Thomas 1980) have not addressed the subject in detail. To concisely define herbage disappearance, we first must define two other terms. The above-ground herbage mass (Hodgson 1979) or the standing crop (Society for Range Management 1974) are the total mass of herbage per unit area of ground at any time. Standing crop is measured from ground level, and is equivalent to herbage mass if the latter is measured from ground level (Hodgson 1979). We can then define herbage disappearance as the loss of herbage from the standing crop associated with senescence, harvest, grazing, trampling, defecation, decay, weather, or other causes. More will be said later about standing crop, but given a standing crop, the herbage disappearance rate (HDR) can be defined as the rate per unit area of herbage dry-weight loss from the above causes and can be expressed in $\mathrm{kg}$ / ha-day (Table 1). By differentiation and integration of HDR with respect to time, the rate of change in $H D R$ and the cumulative herbage disappearance (CHD), respectively, can be derived (Table 1). Thus, cumulative herbage disappearance, herbage disappearance rate, and rate of change in herbage disappearance rate are a complete time-dynamic description of herbage disappearance.

\section{Herbage Accumulation}

With 3 variables each describing herbage growth and herbage disappearance, 3 others can be derived describing the net differences between corresponding pairs of variables. Thus, we define net herbage accumulation rate (NHAR) as the difference between herbage growth rate and herbage disappearance rate, i.e., NHAR = HGR - HDR (Table 1). NHAR is equivalent to net crop growth rate as defined by Thomas (1980). Differentiation of NHAR with respect to time gives the rate of change in $N H A R$, with units of

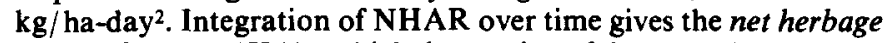
accumulation (NHA), which has units of $\mathrm{kg} / \mathrm{ha}$. Net herbage accumulation expresses the difference between cumulative herbage growth and cumulative herbage disappearance over a period of time (Table 1). Thus, the growth and disappearance columns of Table 1 are basic variables used to derive corresponding variables in the accumulation column. Measurement of any 2 variables in a row (Table 1) allows calculation of the third variable in that row.

\section{Classification of Variables}

The variables described in Table 1 are useful for describing herbage dynamics in modeling or field research (the rate of change variables in row 3 are useful mainly in modeling). Forrester (1961) described features of system structure, including 2 of importance here, level and rate. He defined levels as accumulations within a system, and rates as instantaneous flows between levels in a system. 
Table 1. Summary of basic variables with appropriate units describing herbage growth, disappearance, and net accumulation.

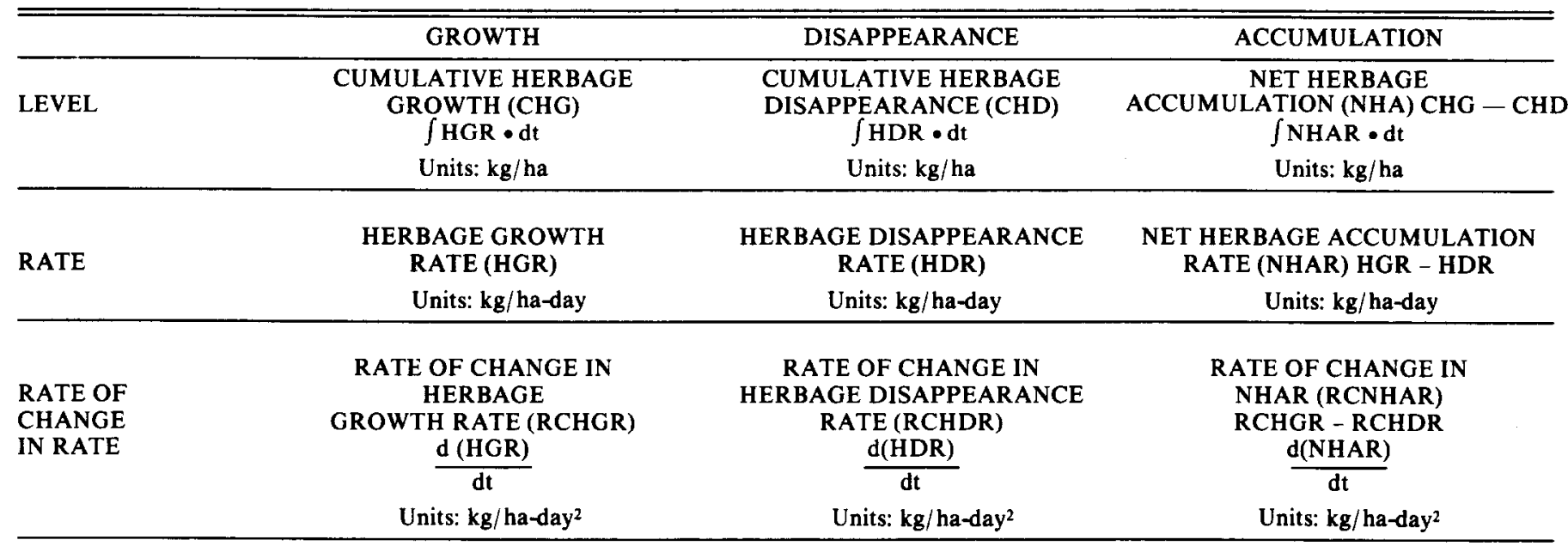

If a system is brought to rest, levels continue to exist but rates do not (Forrester 1961). In modeling herbage dynamics with the variables in Table 1, cumulative herbage growth, cumulative herbage disappearance, and net herbage accumulation would normally be level variables. HGR, HDR, and NHAR are rate variables, and the variables in row 3 are rates of change in rates.

\section{Standing Crop and Herbage Mass}

Standing crop (Society for Range Management 1974) or herbage mass (Hodgson 1979) can be expressed in terms of variables in Table 1. Standing crop is the amount of herbage per unit area at any time, and can be expressed as $\mathbf{S C}=\mathbf{S C}_{0}+\mathrm{NHA}$, where $\mathrm{SC}_{0}$ is initial standing crop at time $t_{0}, S C$ is the standing crop at time $t$, and NHA is net herbage accumulation during the period of time $t-t_{0}$. Standing crop is a measure of the state of a sward (Hodgson 1981). It is also normally a level as defined by Forrester (1961), because it exists if an herbage system is brought to rest, and because conceptually it is an accumulation. Unlike cumulative herbage growth, cumulative herbage disappearance, and net herbage accumulation, which are calculated over some implicit or explicit period of time, standing crop is defined at one point in time. A change in standing crop ( $\triangle S C$ ) over some period of time ( $\left.t-t_{0}\right)$ equals NHA, as can be seen by rearranging the equation above, i.e., $\Delta \mathrm{SC}=\mathrm{SC}-\mathrm{SC}_{0}=$ NHA.

\section{Uses in Research}

Because growth and disappearance are continuous in most swards, and because they respond differently to variations in management, simple estimates of net changes in herbage may not adequately describe the effects of environment or management (Hodgson 1981). To describe and compare effects of different grazing systems, we need independent measurements of herbage growth and disappearance. This usually involves measurements of life histories of individual plants along with spatial and temporal patterns of defoliation of individual shoots and plant parts (Hodgson 1981). There have been several recent studies (Gammon and Roberts 1978, Briske and Stuth 1982) of defoliation under different types of grazing management. Measurements of herbage defoliation, herbage senescence, and other factors contributing to disappearance should be made as a matter of course in field grazing studies. Where herbage disappearance is difficult to measure directly, indirect calculation of disappearance is possible if accum- ulation and growth are measured. With accumulation measurements alone, indirect calculation of disappearance is not possible. Without measurement of growth or disappearance, measurement of net herbage accumulation by a series of standing crop measurements says little about the effects of different management practices on growth and disappearance of herbage. In range research, we have frequently been concerned with measuring changes in standing crop and have learned comparatively little about herbage dynamics. The variables in Table 1 provide a framework for mathematically describing and comparing herbage dynamics under different grazing systems. More attention spent measuring variables in columns 1 and 2 will allow better interpretation of standing crop and the variables in column 3 . Consideration and execution of these more detailed measurements within a mathematical framework as described here would be an important refinement in our grazing research.

\section{Literature Cited}

Abouguendia, Z.M., and W.C. Whitman. 1979. Disappearance of dead plant material in a mixed grass prairie. Oecologia 42:23-29.

Briske, D.D., and J.W. Stuth. 1982. Tiller defoliation in a moderate and heavy grazing regime. J. Range Manage. 35:511-514.

Deshmukh, I.K., and M.N. Baig. 1983. The significance of grass mortality in the estimation of primary productivity in African grasslands. Afr. J. Ecol. 21:19-23.

Forrester, J.W. 1961. Industrial dynamics. MIT Press, Cambridge.

Gammon, D.M., and B.R. Roberts. 1978. Patterns of defoliation during continuous and rotational grazing of the Matopos Sandveld of Rhodesia. 3. Frequency of defoliation. Rhod. J. Agr. Res. 16:147-164.

Hodgson, J. 1979. Nomenclature and definitions in grazing studies. Grass and Forage Science 34:11-18.

Hodgson, J. 1981. Sward studies: objectives and priorities. Chapter 1 In: J. Hodgson, R.D. Baker, A. Davies, A.S. Laidlaw and J.D. Leaver, eds. Sward measurement handbook. British Grassland Society, Berkshire, UK.

Ohiagu, C.E., and T.G. Wood. 1979. Grass production and decomposition in Southern Guinea Savanna, Nigeria. Oecologia 40:155-165.

Pearson, H.A. 1975. Herbage disappearance and grazing capacity of southern pine bluestem range. J. Range Manage. 28:71-73.

Society for Range Management. 1974. Glossary of terms used in range management, 2nd ed.

Thomas H. 1980. Terminology and definitions in studies of grassland plants. Grass and Forage Science 35:13-23. 